\title{
COMMUNICATIONS
}

\section{VASCULARIZATION OF THE PRIMARY OPTIC PATHWAYS*}

\author{
BY \\ J. FRANÇOIS, A. NEETENS, AND J. M. COLLETTE \\ From the Ophthalmological Clinic of the University of Ghent, and \\ the Radiological Clinic of the University of Liége, Belgium
}

FIRST we will study the macroscopic or extra-tissular, and afterwards the microscopic or intra-tissular vascularization of the primary optic pathways. The latter has been especially studied by microradiographic examination of sections $0 \cdot 1-0.5 \mathrm{~mm}$. thick after injecting Heyden's thorotrast.

\section{(A) Macroscopic (eXtra-tissular) Vascularization OF THE Primary Optic Pathways}

The central retinal artery, though making use of the optic nerve to reach the retina, supplies only the latter.

The optic nerve itself is supplied on the one hand by the central artery of the optic nerve-an axial system derived from the ophthalmic artery-and on the other hand by peripheral vessels localized in the pia mater and dependent not only on the ophthalmic artery but also on the ciliary arteries and sometimes even on the extra-optical part of the central retinal artery (Fig. 1).

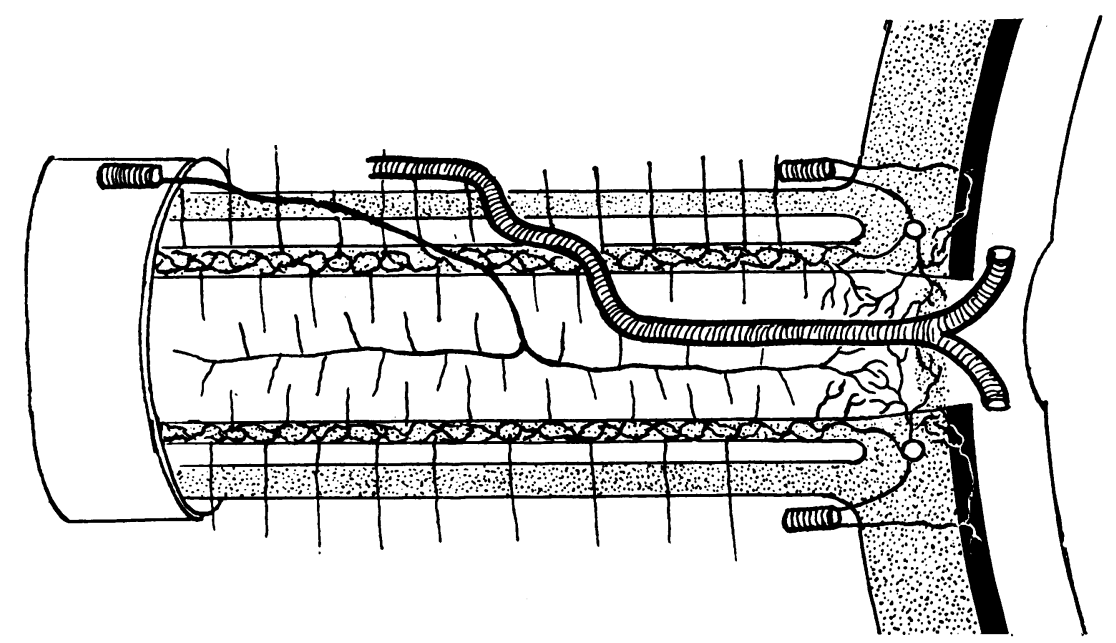

FIG. 1.-Intra-orbital part of the optic nerve (François and Neetens, 1954, Fig. 9, p. 486).

The central artery of the optic nerve, seen only at the level of the intra-

* Read at the combined meeting of the Society of British Neurological Surgeons and the 36th Annual Meeting of the Irish Ophthalmological Society in Dublin, May 16-18, 1957. 
orbital part of the nerve, divides into two branches, anterior and posterior, both of which are localized in the nerve axis.

The peripheral system, the arteries of which reach the surface of the optic nerve perpendicularly and divide dichotomously, is reinforced in front, at the level of the lamina cribrosa of the sclera, by the vessels of the circle of Zinn-Haller derived from the short posterior ciliary arteries, and behind, at the level of the intracanalicular and intracranial sections of the optic nerve, by a marked increase in the number of large arterioles, the trophic role of which becomes preponderant at this level.

The intracranial optic nerve and the optic chiasma are supplied by the internal carotid, the anterior cerebral, and the anterior communicating arteries.

As to the chiasma, our observations have led to the following conclusions:

(1) The only specific and well-defined artery which we found at the level of the chiasma was the chiasmal artery, which derives from the anterior communicating artery and supplies the central part of the chiasma (Fig. 2, opposite). However, this vessel, which has not been described before, was found in only one-third of our cases.

(2) The only characteristic arteriolar formation is the prechiasmal arch over $180^{\circ}$.

(3) The branches of the internal carotid artery reach the chiasma at its inferior temporal surface.

(4) The branches of the anterior communicating and the anterior cerebral arteries reach the chiasma at its antero-superior surface.

(5) Anastomoses can be observed between the small arterioles at the surface of the chiasma.

(6) All these arterioles proceed to the chiasma, either directly or-more frequently - by way of the prechiasmal arch.

(7) The ophthalmic, anterior choroidal, middle cerebral, and posterior communicating arteries are only slightly and at best indirectly involved in the vascularization of the chiasma.

The optic tract is likewise supplied by the posterior communicating artery as well as by the anterior choroidal artery.

The surface of the external geniculate body is covered by a dense anastomotic network; this is formed by branches of the anterior choroidal, and especially by branches of the posterior cerebral artery (posterior choroidal arteries) and sometimes also by a branch of the superior cerebellar artery. From this superficial network arise arterioles which penetrate obliquely the subjacent organ.

A comparison of the different parts of the primary optic pathways leads to the following conclusions:

(1) At two ends-at the level of the intrabulbar and juxtabulbar part of the optic nerve and at the level of the external geniculate body-the vascularization becomes singularly important: in front are the central retinal artery, the anterior branch of the central artery of the optic nerve, and the ciliary arteries, and behind are the posterior cerebral and anterior choroidal arteries and the branches of the vascular system of the optic tract. 


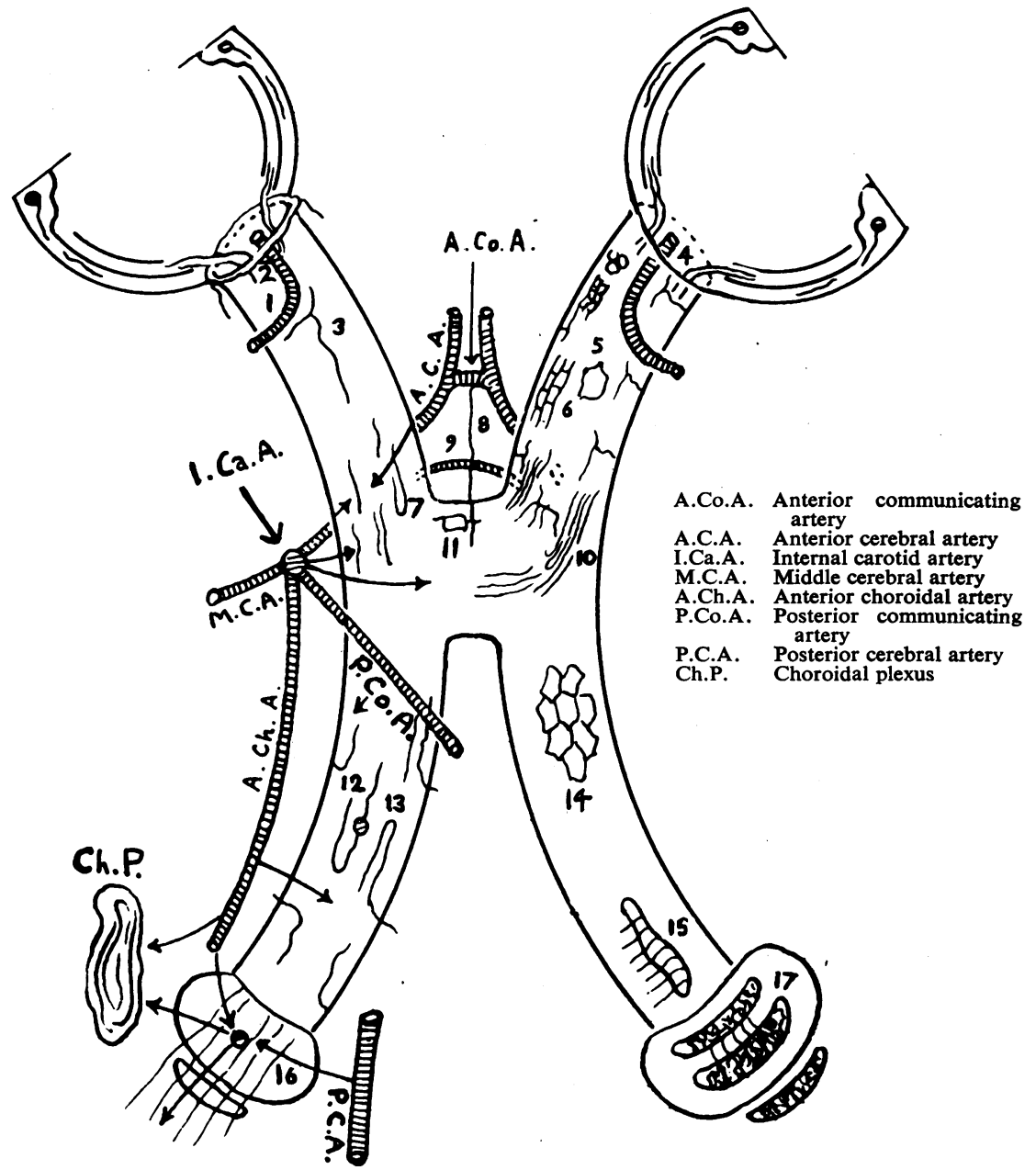

FIG. 2.

Central retinal artery

Collateral vessels of central retinal artery supplying only the retina

Central optic nerve artery (anterior and posterior branch)

Capillaries and precapillaries of optic origin localized in fascicular layer of retina

Specific capillaries of optic nerve: transverse units of pentagonal shape

Specific capillaries of optic nerve: longitudinal units of square shape

Nasal side of intracranial optic nerve: precapillaries curving back in hairpin bends

Chiasmal artery

Prechiasmal arcade

Temporal side of chiasma: capillaries curving back in hairpin bends

Capillary junction pattern of middle part of chiasma

Capillaries of optic tract arising from perforating arteries

Intra-tissular arterioles of optic tract with hairpin curves

Intra-tissular arterioles of optic tract with hairpin curves
Specific capillary structure of optic tract: polygonal, often hexagonal meshes

Specific capilary structure of optic tract: polygonal, often hexagonal meshes
Quadrangular capillary structure of optic tract towards external geniculate body

Perforating arterioles and arterioles supplying the external geniculate body arising from superficial anasto-

motic network
Two types of capillary of external geniculate body characteristic of cellular and fascicular layers

(2) The intra-orbital part of the optic nerve possesses an axial trophic system (central artery of the optic nerve). At the level of the optic tract there is no single axial artery; but several arterioles-extending in an antero-posterior direction and with a reduced lumen-form what may be called a bundled axial system. 
(B) Microscopic (intra-tissular) Vascularization of the Primary

Optic Pathways

(1) Retina.-Surrounding the optic disc, and at a distance of about two disc diameters, are capillaries which provide the vessels proper to the optic nerve (Figs 3 and 4). They curve back at the level of the edge of the disc, and then assume a radial and nearly linear course. They form a dense

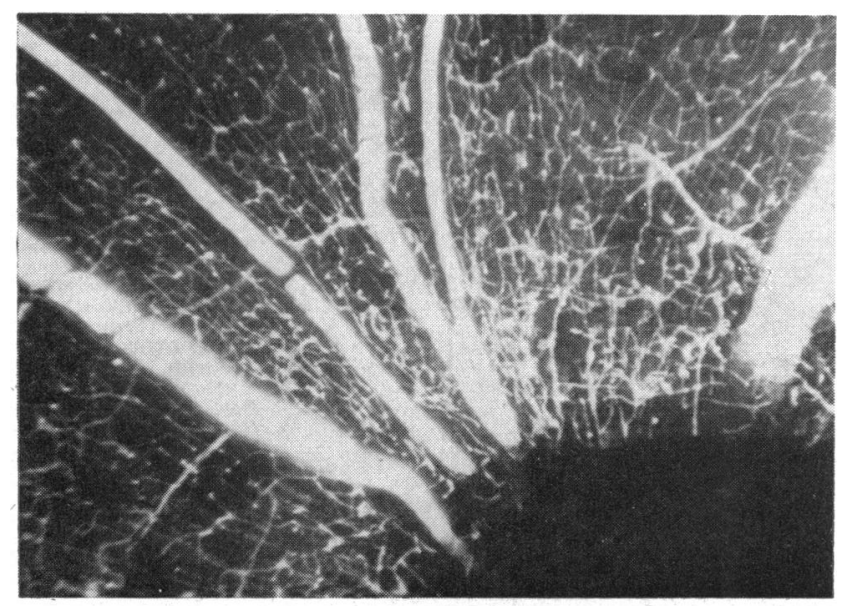

FIG. 3.-Microradiograph of retinal peripapillary capillary network. Thorotrast $\times 75$.

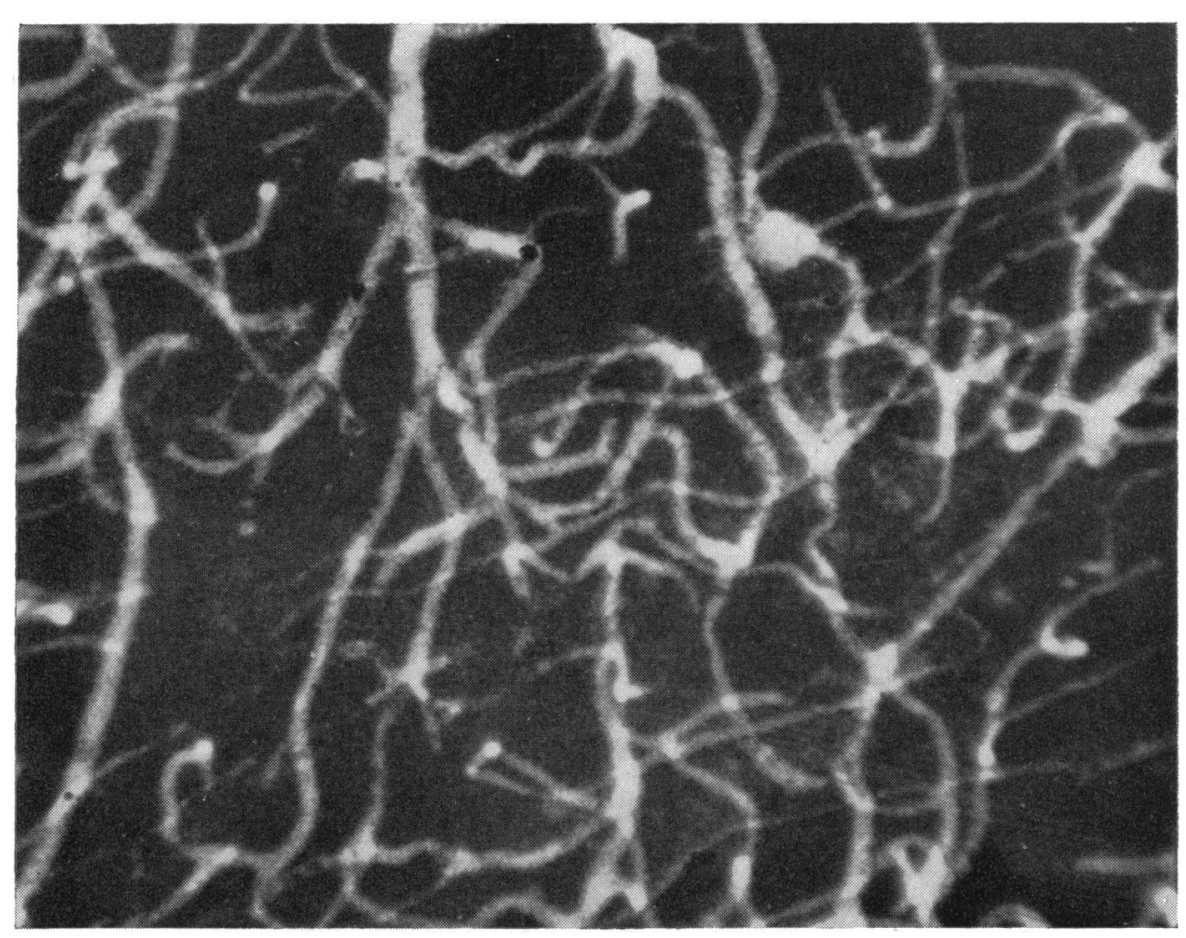

FIG. 4.-Enlargement of part of Fig. $1 . \quad \times 190$. 
network, the appearance of which is very different from the bunched, harmoniously disposed, and free appearance of the other retinal capillaries.

The peripapillary capillaries of optic origin, which may have the calibre of precapillaries and which in fact create a cilio-retinal anastomosis, are localized in the fascicular layer of the retina and anastomose with the capillaries which are directly dependent on the central retinal artery. The latter, arranged in a double layer, involve the entire membrane, but the density of the network diminishes towards the periphery.

Only round the disc does the layer of retinal nerve fibres have a proper vascularization. Otherwise there are generally only precapillary vessels; the capillaries proper are localized within and outside the layer of bipolar cells. The retinal layers localized outside the external plexiform layer are devoid of vessels, which does not necessarily mean that their supply is dependent on the choriocapillaries.

(II) Lamina Cribrosa Sclerae and Optic Disc.- The central retinal artery as a rule gives off no branch to this region. Yet the region has an abundant vascularization, the vessels originating from other sources, as follows:

(1) Scleral

(a) Capillary ramifications originating from the circle of Zinn-Haller formed by branches of the short posterior ciliary arteries. These ramifications form anastomoses with the capillaries of the anterior branch of the central artery of the optic nerve;

(b) Ramifications of the short posterior ciliary arteries which irrigate the sclera and then continue towards the lamina cribrosa.

(2) Neural

(a) Branches issuing from the vascular network of the pia mater;

(b) Ramifications of the anterior branch of the central artery of the optic nerve which anastomose with those forming the circle of Zinn-Haller.

(3) Choroidal.-A few recurrent branches of the choroid vessels.

(III) Intra-Orbital Part of Optic Nerve.-The intra-orbital part of the optic nerve has a characteristic capillary network, especially in its middle third, and shows two welldefined types of units:

(1) Longitudinal units running in an antero-posterior direction inside the interfascicular spaces (Fig. 5). From these units derive all the branches contributing to the formation of other vascular elements.

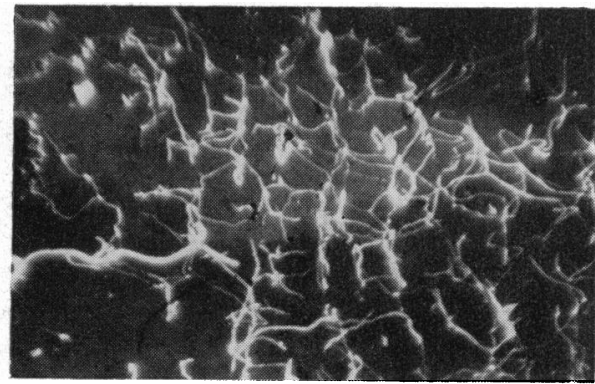

FIG. 5.-Microradiograph of intra-orbital optic nerve, middle part, longitudinal section. Thorotrast $\times 50$. 
(2) Transverse units of pentagonal and sometimes circular shape surrounding each bundle of nerves and forming complete or incomplete rings which are found at regular intervals throughout the length of the bundle (Fig. 6).

The capillaries deriving from these two types of units form an apparently inextricable network which shows more or less square meshes in longitudinal sections.

Posteriorly, the vascularization becomes less dense (Fig. 7) and the transverse capillary units stretch to lose their pentagonal shape; anteriorly, towards the optic disc, the capillary network becomes denser and more irregular.

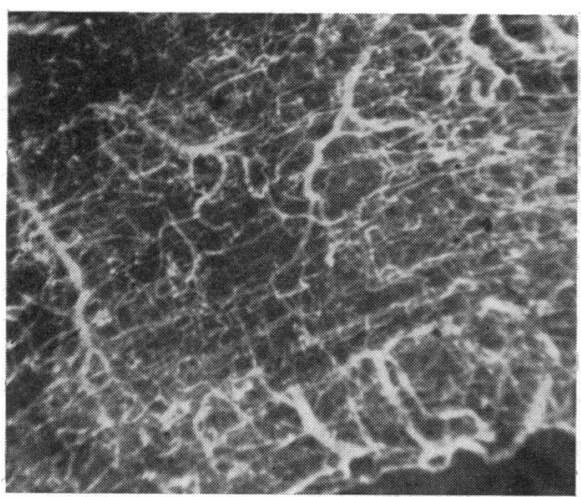

FIG. 6.-Microradiograph of intra-orbital optic nerve, middle part, transverse section. Thorotrast $\times 70$.

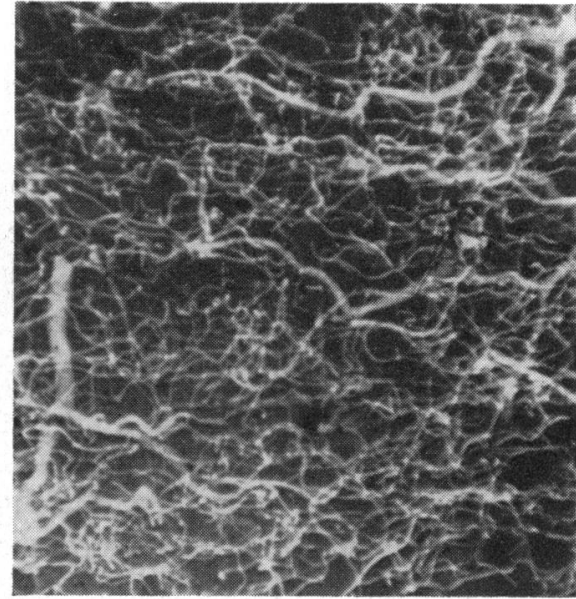

FIG. 7.-Microradiograph of intra-orbital optic nerve, anterior part, longitudinal section. Thorotrast $\times 70$.

(IV) Intracanalicular and Intracranial Part of Optic Nerve.-These parts differ from the intra-orbital part of the optic nerve in that there is no axial artery but only precapillaries, which are less numerous than at the level of the optic tract.

The capillary network shows the following characteristics:

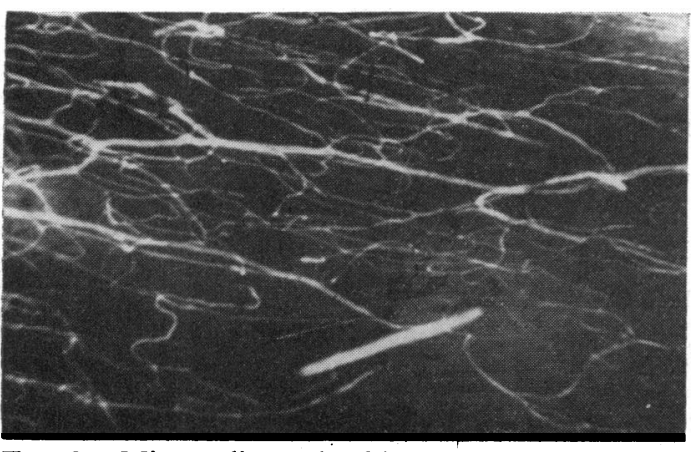

FIG. 8.-Microradiograph of intracranial optic nerve, longitudinal section. Thorotrast $\times 75$.

(a) The transverse capillaries are stretched in an antero-posterior direction instead of remaining in the same frontal plane.

(b) There is no systematization. The distribution of the capillaries is irregular; considerable disorder exists both in their direction and in their mode of division (Fig. 8); angular forms are frequent. 
(c) On the temporal side the capillaries, and on the nasal side especially the precapillaries, sometimes curve back in hairpin fashion; this phenomenon is also seen in the arterioles, and more frequently at the level of the optic tract.

(V) Chiasma.-Seven different zones can be distinguished (Fig. 9).

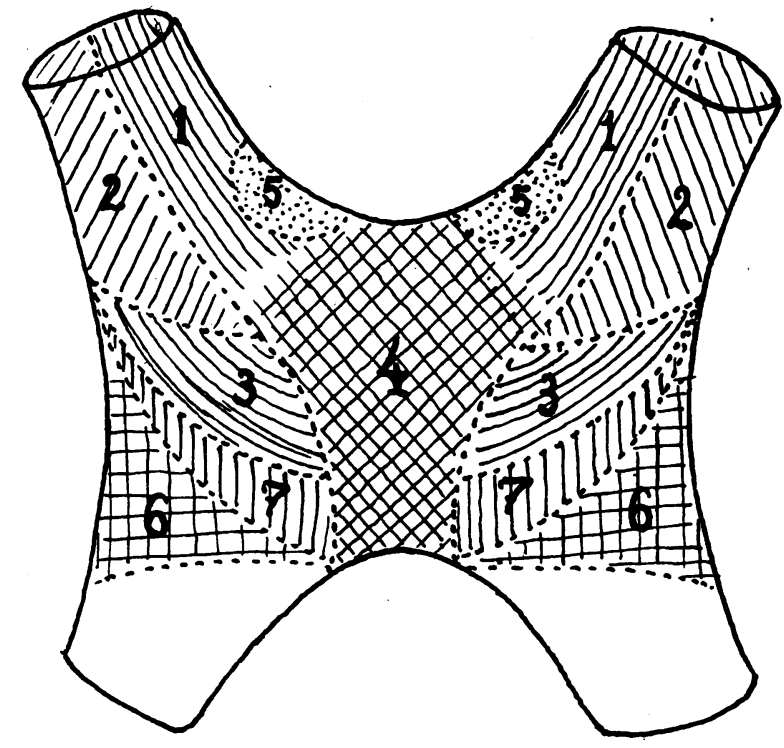

Fig. 9.-The seven zones of the chiasma (François, Neetens, and Collette, 1956b, Fig. 2, p. 733).

(1) A zone occupying the nasal half of the optic nerve and the anterior part of the chiasma, showing fine and irregularly rectilinear capillaries following the direction of the fibres and becoming more irregular in the chiasma proper (Fig. 10, overleaf). These are the longitudinal units of the optic nerve which are prolonged into the chiasma, where they curve back towards the median plane, describing a loop with an anterior concavity. The hairpin curves are less numerous here than in Zone 2.

(2) A zone occupying the temporal half of the optic nerve and the anterior part of the chiasma, showing capillaries slightly larger than those in Zone 1 (Fig. 11, overleaf). These capillaries run in all directions and make an irregular angular network.

(3) A third zone, continuing from the preceding and extending to the sagittal plane, showing finer and more regular capillaries, reminiscent of those in Zone 1. The capillaries of the temporal part of the optic nerve do not continue to the optic tract but curve back to the sagittal plane after having penetrated the chiasma.

(4) The median zone, more or less hexagonal, extends from the anterior border to the posterior border of the chiasma. Its capillaries are larger and run in a transverse direction, connecting the left and right sides. These are the junction capillaries (Fig. 12, overleaf) from which finer capillaries arise. The capillary network is less dense and less tortuous in the central part than 


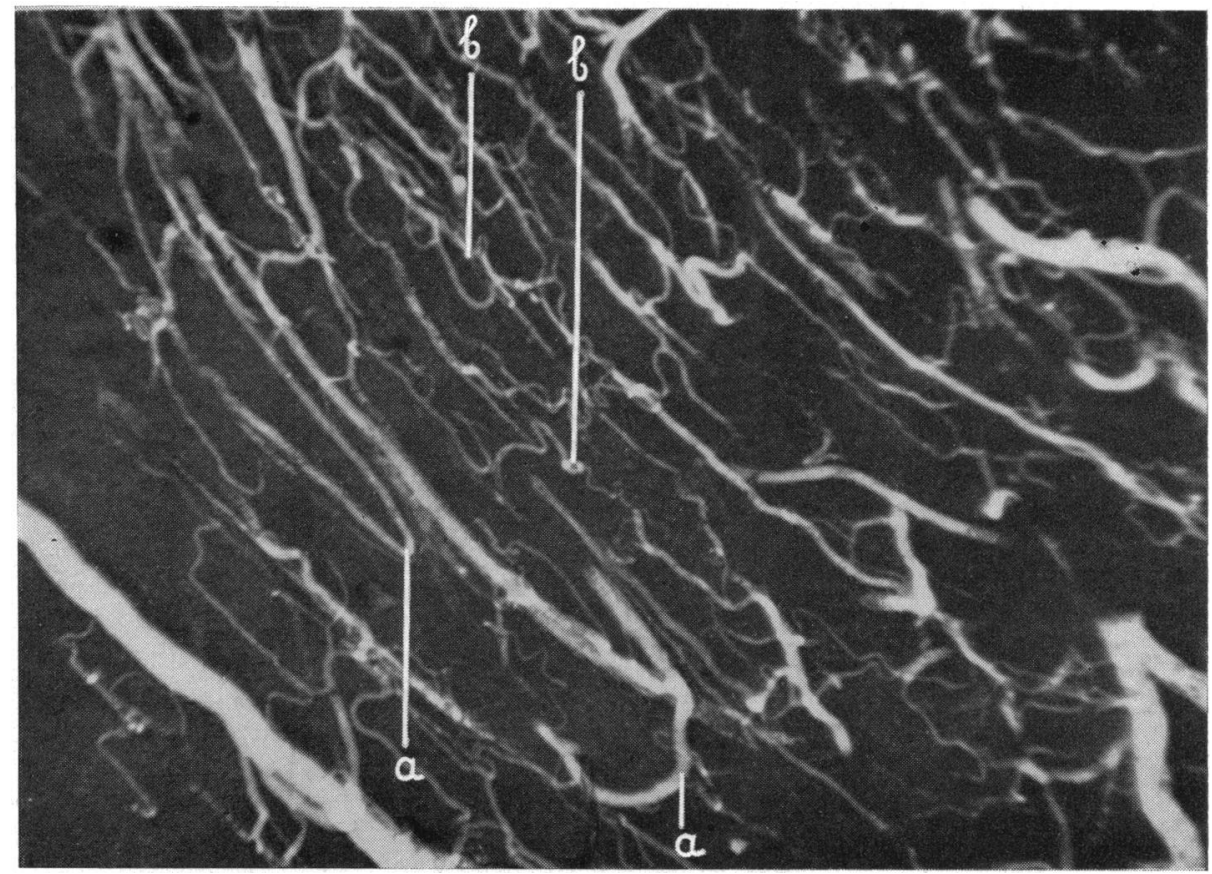

Fig. 10.-Microradiograph of chiasma, Zone 1, antero-posterior section. Thorotrast $\times 75$. (François and others, 1956b, Fig. 3, p. 733).

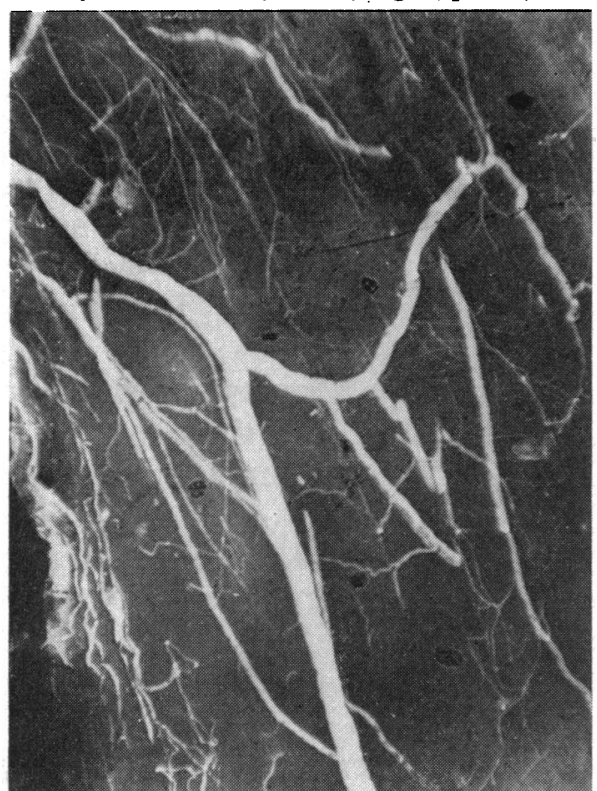

Fig. 11.-Microradiograph of chiasma, Zone 2, antero-posterior section. Thorotrast $\times 52 \cdot 5$.

in the paramedian parts. The capillaries generally follow the track of the fibres. This is the only chiasmal zone with characteristic capillaries which form true meshes and show a regular aspect throughout. 


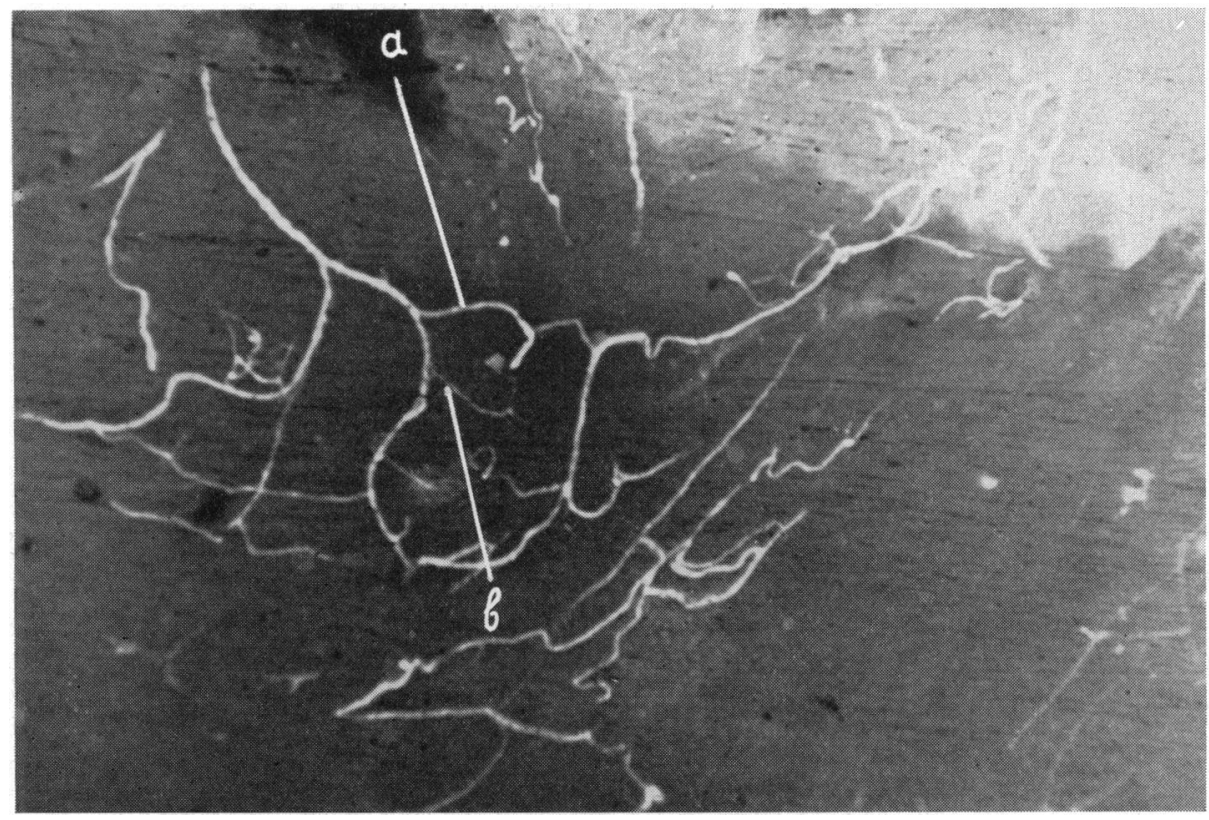

FIG. 12.-Microradiograph of chiasma, Zone 4, antero-posterior section. Thorotrast $\times 75$. (François and others, 1956b, Fig. 7, p. 736).

(5) In the transitional region between the optic nerve and the chiasma, there exists, on the nasal side, a zone in which the capillaries are fairly fine, extremely irregular, and very confused. Capillaries with no well-defined directional pattern show abrupt changes in direction with rounded angles.

(6) The sixth zone consists of a triangular region, with its base on the temporal border of the chiasma and directed towards the posterior border. Fairly important capillaries are found here and those on the temporal side especially are closely similar to the capillaries of the optic tract (Fig. 13).

Fig. 13.-Microradiograph of chiasma, Zone 6 , antero-posterior section. Thorotrast $\times 52 \cdot 5$.

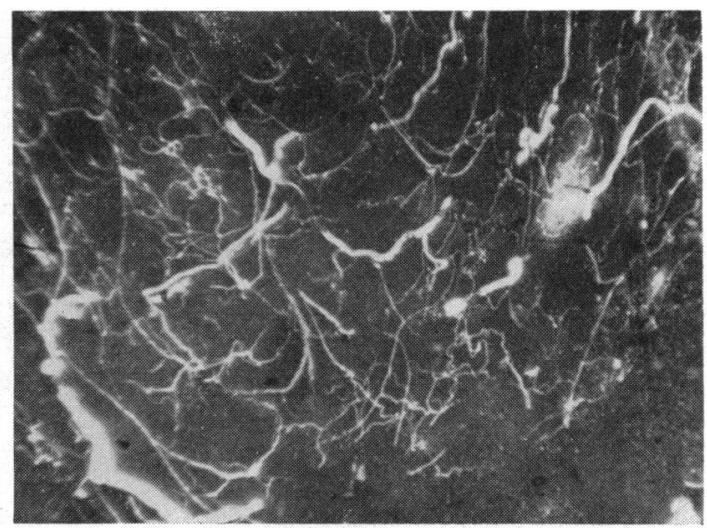

(7) The last zone is one of transition between the third and the sixth 
zones. It has the form of a half-moon and stretches from the temporal border of the chiasma to the median zone. It includes tortuous capillaries, fairly large but not numerous, which form a network with no apparent systematic arrangement and no well-defined structure (Fig. 14).

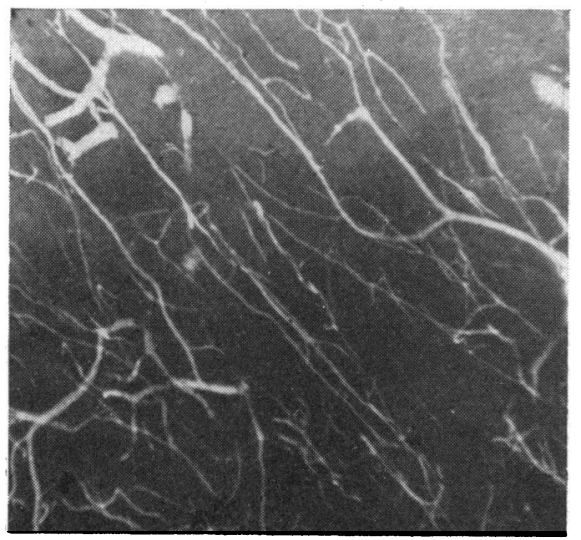

FIG. 14.-Microradiograph of chiasma, Zone 7, antero-posterior section. Thorotrast $\times 75$.

The significance of these different zones is not known, but there is no congruence between the myelo- and the angio-architecture.

(VI) Optic Tract:-Longitudinal sections show the following structures (Figs 15 and 16):

FIG. 15.-Microradiograph of optic tract, longitudinal section. Thorotrast $\times 52 \cdot 5$.
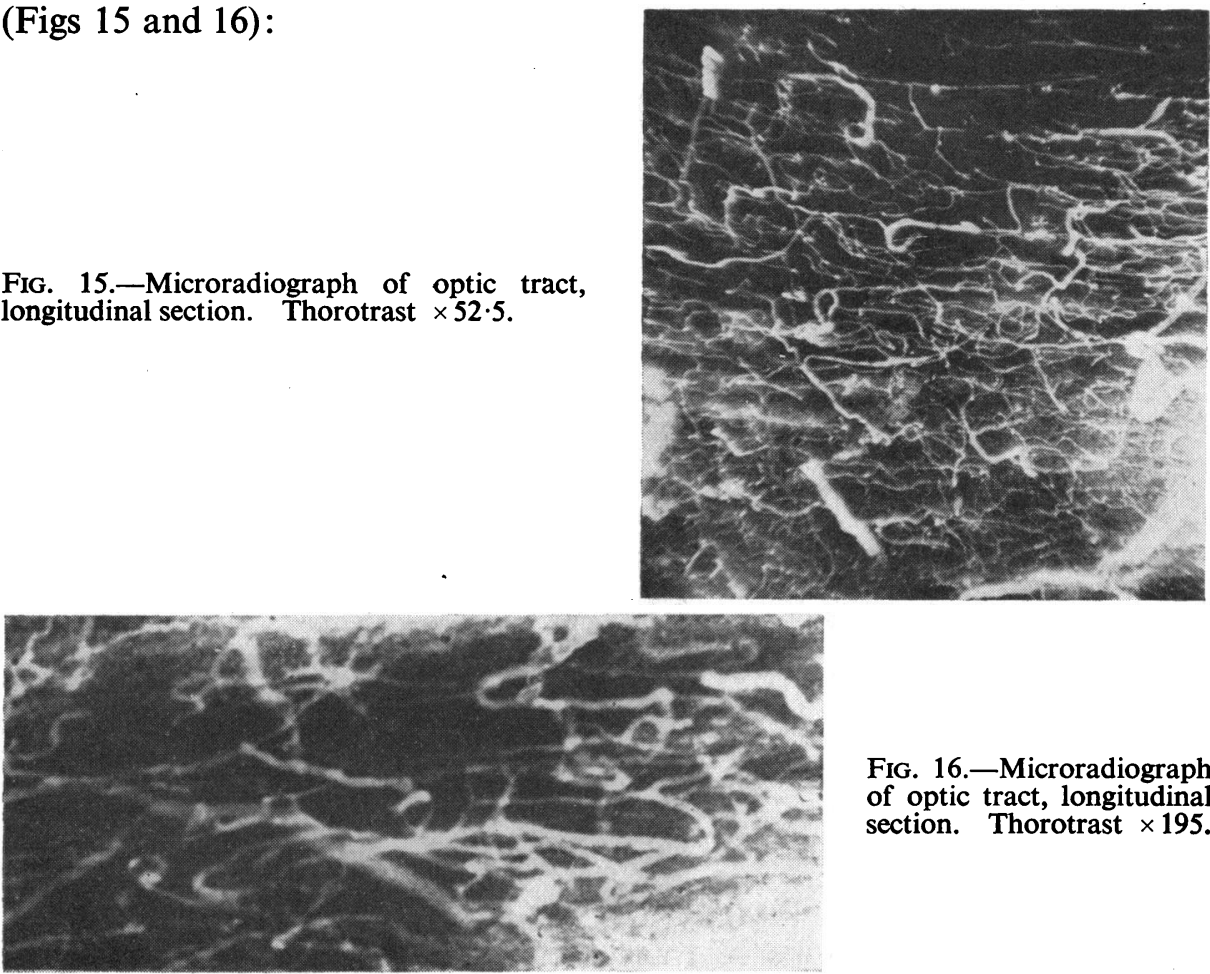

FIG. 16.-Microradiograph of optic tract, longitudinal section. Thorotrast $\times 195$. 
(1) Large and irregularly polygonal meshes which are often hexagonal.

(2) These meshes alternating with other meshes which are straighter, more elongated, and more fusiform.

(3) At the level of certain points of intersection a capillary is seen to take a circular or ellipsoid course, and to give rise to two transverse and two longitudinal capillaries; this condition is characteristic of the optic tract.

Transverse sections show the following arrangements:

(1) The capillaries never form a complete ring round the bundles of nerves.

(2) Anastomotic capillaries are localized in an oblique direction.

(VII) External Geniculate Body.-The capillary network of the external geniculate body, which anastomoses with other capillary networks, constitutes a more or less spherical formation, readily recognizable by its extreme abundance. It is composed of several layers of capillaries showing two distinct alternating types (Figs 17 and 18, overleaf):

(1) Capillaries which form extremely close meshes, round or slightly ellipsoid, and arranged in a cluster, which are typical of the cellular layers of the geniculate body; each group of nerve cells would seem to have its cluster of capillaries.

(2) Capillaries which are more linear, more widely spaced, and slightly larger, and partly arise from the optic tract; they are peculiar to the fascicular layers where they form a network similar to that of the optic tract.

\section{(C) Comparison between the Retina AND the External GeNICULATE BoDY}

A comparison between the retina-starting point of the first neuron of the optic pathways-and the external geniculate body-the first relay-shows the following points of similarity:

(1) The receptor part of the retina, localized outside the external plexiform layer, is avascular; this part has no corresponding part at the level of the external geniculate body.

(2) The bipolar and ganglion cells of the retina correspond to the cellular layers of the external geniculate body, while the layer of retinal optic fibres corresponds to the fascicular layers of the ganglionic relay.

As regards vascularization, too, there are several similarities between the retina and the external geniculate body:

(1) The peripapillary capillaries, dependent on the vessels belonging to the optic nerve and occupying the fascicular layer of the retina, are analogous to those of the fascicular layers of the external geniculate body, which partly arise from the optic tract.

(2) In both organs the fascicular layers are relatively poorly vascularized, whereas the vascularization of the cellular layers is abundant. 


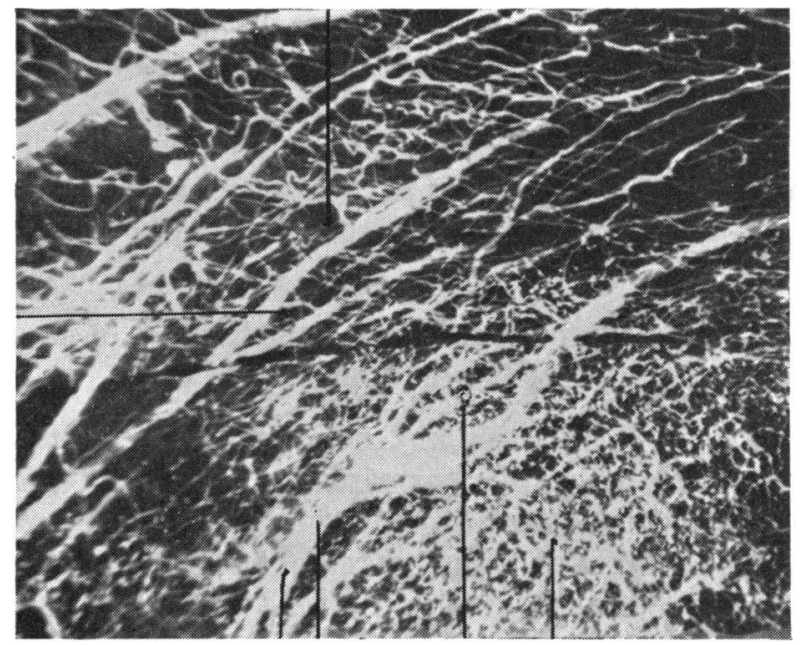

FIG. 17.-Microradiograph of lateral geniculate body, parasagittal section. Thorotrast $\times 75$. (François and others, 1956a, Fig. .10, p. 350).

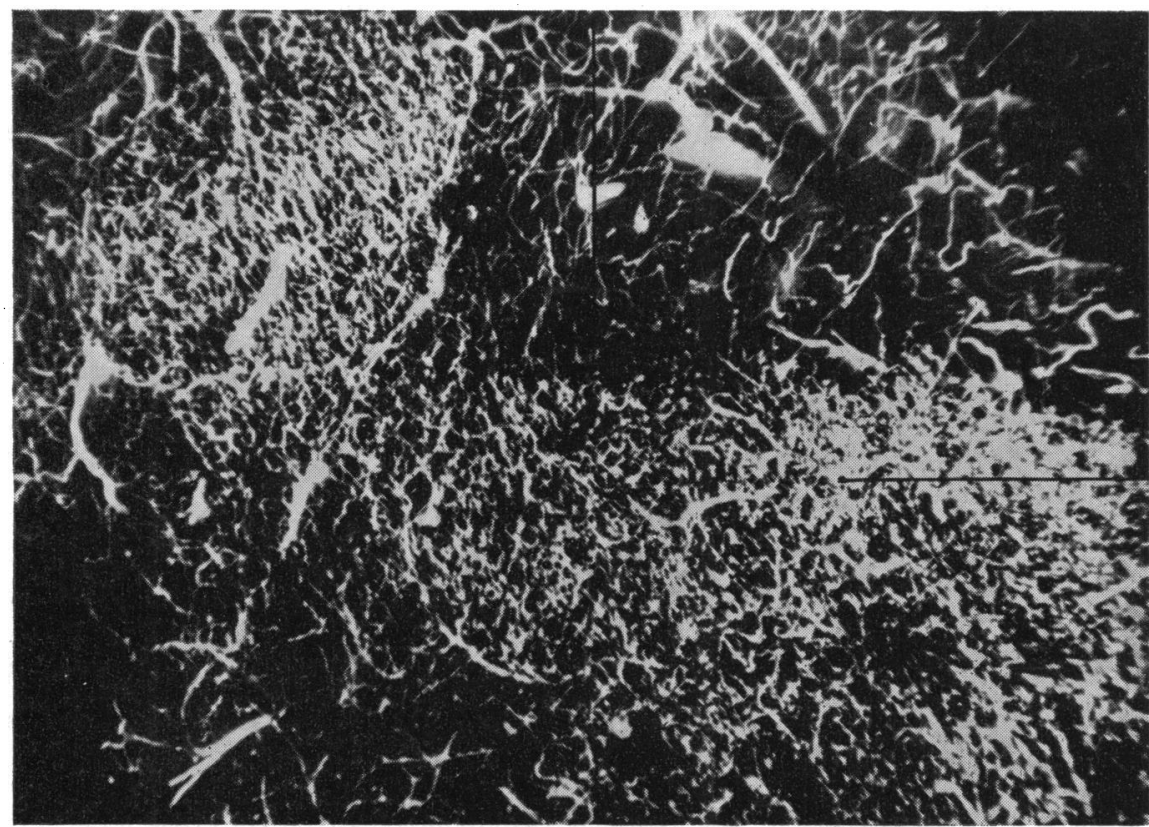

FIG. 18.-Microradiograph of lateral geniculate body, parasagittal section. Thorotrast $\times 75$. (François and others, 1956a, Fig. 13, p. 352).

(3) The ellipsoid or round meshes formed by the capillaries are found both in the retina and in the external geniculate body, where they are smaller and more tightly packed.

(4) The vascular branches extending to a certain part of the organ remain individual and isolated both in the retina and in the ganglionic relay. 
The numerous differences which appear are more apparent than real:

(1) The retina is supplied by a single specific artery (the central retinal artery). The external geniculate body depends on an anastomotic network formed by several arteries.

(2) At the level of the retina the capillaries form a double loop round the bipolar cells; in the external geniculate body nearly every cell or group of cells is surrounded by capillaries.

(3) The branches of the central retinal artery do not extend to other regions, but are undoubtedly terminal; at the level of the external geniculate body there are perforating arteries which in their course give off collaterals.

These differences are due to the two following facts:

(1) The retina constitutes an extremely thin membrane, not exceeding $0 \cdot 2-0.3 \mathrm{~mm}$. in thickness; it is therefore practically two-dimensional. The geniculate body, however, is definitely three-dimensional, and thus requires an enrichment of the network either by arterioles or by capillaries.

(2) The retina is the starting-point of the optic pathways, whereas the external geniculate body is merely a relay. This explains why the latter depends on various non-terminal arteries, as is the case with all ganglionic relays.

Despite apparent differences, therefore, it can be said that the structure of the retina is identical with the architecture of the external geniculate body. The vascularization of the geniculate body does in fact show the spatial construction of the retinal vascularization.

These capillary findings afford corroborative evidence of the interrelationship between the retina and the brain-a fact long established in embryology and anatomy.

\section{(D) Comparison between the Intra-Orbital Part of the Optic NeRVE AND THE OptiC TRACT}

There are numerous discrepancies between the vascularization of the intra-orbital part of the optic nerve and that of the optic tract:

(1) In the intra-orbital part of the optic nerve there exists a specific axial vascular system represented by the central artery of the optic nerve. No single axial system exists at the level of the optic tract.

(2) The arterioles penetrate the interior of the optic nerve following a course perpendicular to its surface. They form branches to the nerve axis which maintain their original direction, whether this be anterior or posterior. The arterioles penetrate the interior of the optic tract following an oblique, slightly sloping course. They form branches which curve back in hairpin fashion, completely changing their direction. Since these arterioles depend on two different arteries (the anterior choroidal and the posterior communicating artery), it can be said that a double vascularization exists at the level of the optic tract which is not found at the level of the optic nerve. 
(3) The capillary network of the optic nerve shows a structure completely different from that of the optic tract (Table I). Briefly, the typical aspect of the capillary network of the optic nerve shown in transverse sections is roughly repeated at the level of the optic tract, but in longitudinal sections. In the same manner, the quadrangular capillary meshes of the optic nerve seen in longitudinal sections are more or less repeated at the level of the optic tract, but in transverse sections.

TABLE I

\begin{tabular}{|c|c|c|c|}
\hline Structure & & Optic Nerve & Optic Tract \\
\hline Longitudinal Capillary Unit & .. & $\begin{array}{l}\text { Follows a linear course } \\
\text { and constitutes the } \\
\text { basic structure }\end{array}$ & Does not exist \\
\hline Transverse Capillary Unit & .. & $\begin{array}{l}\text { Specifically pentagonal in } \\
\text { shape }\end{array}$ & Is partly lacking \\
\hline Longitudinal Section & .. & Quadrangular meshes & $\begin{array}{l}\text { Sometimes fusiform and } \\
\text { sometimes polygonal } \\
\text { meshes, often hexago- } \\
\text { nal; characteristic of the } \\
\text { tract }\end{array}$ \\
\hline Transverse Section & .. & $\begin{array}{l}\text { Pentagonal meshes, cha- } \\
\text { racteristic of the optic } \\
\text { nerve }\end{array}$ & No characteristic meshes \\
\hline
\end{tabular}

The continuity of the capillary network is less systematized and more irregular at the level of the optic tract than at the level of the optic nerve. No long antero-posterior capillaries are found, the longitudinal continuity being ensured by transverse capillaries.

(4) The structure of the optic nerve resembles that of the peripheral nerves whereas that of the optic tract approaches that of the white matter of the brain.

There are therefore also certain analogies between the two organs, in that whereas the capillaries of the optic tract continue towards the fascicular layers of the external geniculate body, those of the optic nerve are prolonged in the fascicular layer of the retina.

(E) General Considerations

A change in the nutrition of an organ depends in general on an alteration of the arteries, arterioles, precapillaries, or capillaries. The cause of this alteration may be found outside the vessel or within it.

Extravascular causes include intra-tissular proliferative or oedematous processes which flatten the vessels, processes of compression which concern the organ itself or its nutritive vessels, and the cicatricial processes which produce adhesions with retraction as in optochiasmal arachnoiditis. Intravascular causes include arteriosclerosis, spasm, endarteritis, embolism, etc.

The principal characteristics of the vascularization of the primary optic pathways are presented in Table II (opposite). 
TABLE II

\begin{tabular}{|c|c|c|c|c|c|c|c|c|c|c|}
\hline \multirow{3}{*}{ Organ } & \multicolumn{2}{|c|}{ I. } & \multicolumn{4}{|c|}{ II. } & III. & IV. & \multicolumn{2}{|c|}{ v. } \\
\hline & \multirow{2}{*}{\multicolumn{2}{|c|}{ Retina }} & \multicolumn{4}{|c|}{ Optic Nerve } & \multirow[t]{2}{*}{ Chiasma } & \multirow{2}{*}{$\begin{array}{l}\text { Optic } \\
\text { Tract }\end{array}$} & \multirow{2}{*}{\multicolumn{2}{|c|}{ Geniculate Body }} \\
\hline & & & $\begin{array}{l}\text { Intra- } \\
\text { bulbar }\end{array}$ & $\begin{array}{c}\text { Intra- } \\
\text { orbital }\end{array}$ & $\begin{array}{l}\text { Intra- } \\
\text { canali- } \\
\text { cular }\end{array}$ & $\begin{array}{l}\text { Intra- } \\
\text { cranial }\end{array}$ & & & & \\
\hline Function & $\begin{array}{c}\text { Recep- } \\
\text { tion }\end{array}$ & $\begin{array}{l}\text { Con- } \\
\text { duc- } \\
\text { tion }\end{array}$ & $\begin{array}{c}\text { Con- } \\
\text { duc- } \\
\text { tion }\end{array}$ & $\begin{array}{l}\text { Con- } \\
\text { duc- } \\
\text { tion }\end{array}$ & $\begin{array}{l}\text { Con- } \\
\text { duc- } \\
\text { tion }\end{array}$ & $\begin{array}{c}\text { Con- } \\
\text { duc- } \\
\text { tion }\end{array}$ & $\begin{array}{c}\text { Conduc- } \\
\text { tion }\end{array}$ & $\begin{array}{c}\text { Conduc- } \\
\text { tion }\end{array}$ & $\begin{array}{c}\text { Recep- } \\
\text { tion }\end{array}$ & $\begin{array}{l}\text { Conduc- } \\
\text { tion }\end{array}$ \\
\hline $\begin{array}{cc}\begin{array}{c}\text { Arteries and Ar- } \\
\text { terioles }\end{array} & \cdots \\
\end{array}$ & - & + & ++ & + & + & ++ & +++ & ++ & ++ & + \\
\hline $\begin{array}{c}\text { Precapillaries and } \\
\text { Capillaries .. }\end{array}$ & +++ & + & +++ & ++ & ++ & ++ & ++ & ++ & +++ & + \\
\hline Type $\quad \ldots \quad$. & Term & inal & $\begin{array}{l}\text { Ana- } \\
\text { sto- } \\
\text { moses }\end{array}$ & $\begin{array}{c}\text { Central } \\
\text { part } \\
\text { termi- } \\
\text { nal } \\
\text { Peri- } \\
\text { pheral } \\
\text { part } \\
\text { anasto- } \\
\text { motic }\end{array}$ & Anasto & moses & $\begin{array}{c}\text { Possibility } \\
\text { of anas- } \\
\text { tomoses }\end{array}$ & $\begin{array}{c}\text { Anasto- } \\
\text { moses } \\
\text { Double } \\
\text { vascu- } \\
\text { lariza- } \\
\text { tion }\end{array}$ & $\begin{array}{l}\text { More or } \\
\text { less ter- } \\
\text { minal }\end{array}$ & $\begin{array}{r}\text { Possibility } \\
\text { of anas- } \\
\text { tomoses }\end{array}$ \\
\hline
\end{tabular}

\section{CONCLUSIONS}

(1) We have seen that the longitudinal capillary network of the optic nerve is normally continued towards the retina to form there a peripapillary network, which anastomoses with the capillary network proper of the retina. In short, this peripapillary network, which originates either from the circulation of the pia mater, or from the ciliary system, or from the circle of Zinn-Haller, constitutes a kind of cilioretinal vascularization. It explains the atrophic rings that are found around the disc in certain degenerative or atrophic affections of the optic nerve.

(2) The capillary and arteriolar vascularization is denser in and around the disc than in the retina or in the optic nerve itself. This explains the frequency and intensity of papilloedema.

The richness of vessels in the disc, as well as the independence of the central retinal artery during its course through the optic nerve, is also of great significance for the development and pathogenesis of functional disturbances in glaucoma.

(3) Arteriosclerosis may produce lesions not only in the optic nerve, but also in other parts of the optic pathways, either by obliteration of a nutritive artery, which, moreover, may compress the nerve fibres, or by obstruction of a capillary network of greater or lesser significance.

Possible interruption of perioptic arterioles has less effect if there are many of these arterioles (for instance, in the chiasma) or if there are numerous anastomoses (as in the peripheral network of the optic nerve).

However, if the interruption takes place in a more or less isolated or partially terminal artery, such as the central artery of the optic nerve, an acute syndrome is seen to develop, with significant functional signs. Besides 
"infectious or inflammatory" papillitides or optic neuritides, there must exist a papillitis or a "vascular" neuritis, due to spasm or partial or total thrombosis of the central artery of the optic nerve, and comparable to embolism of the central retinal artery. This vascular papillitis, which may be observed, for example, in temporal arteritis, is characterized by oedema or atrophy of the disc with diminution of central vision and perimetrical defects, but possibly with preservation of the peripheral areas of the visual field, since the peripheral nutritive vessels of the optic nerve may remain intact.

(4) In the intracerebral portion of the optic nerve, the precapillary and capillary vascularization is not only irregular but also less dense temporally than nasally, so that the temporal part of the optic nerve is more fragile than the nasal part; certain defects of the nasal area of the field of vision are certainly better explained by inhibition or arrest of the capillary or precapillary circulation than by direct pressure by the sclerotic carotid arteries, the more so as the latter, if they are not rigid, are more readily deformed than the nerve itself.

(5) It is inconceivable that the chiasma, which is profusely supplied by eleven arteries and a whole network of anastomotic arterioles (a prechiasmal arteriolar arcade), should be functionally impaired by the occlusion of one or even more arteries. The functional defects should be attributed to an intra-tissular capillary affection due either to degeneration, or, more frequently, to compression from outside.

(6) In regard to the optic tract, various authors have noticed with astonishment the absence of homonymous hemianopia after ligation of the anterior choroidal artery in order to suppress the action of the corpus striatum (corpus of Luys) in certain cases of extrapyramidal trembling. The absence of this hemianopia can be explained by double vascularization (hairpin curves of the precapillaries originating either from the anterior choroidal artery or from the posterior communicating artery).

However, this hemianopia sometimes exists in cases of ligation of the anterior choroidal artery, since anomalies of the circle of Willis are frequent; in the same way, we also observed complete or partial absence of the posterior communicating artery.

(7) Since the capillary network in the lateral geniculate body, as in the retina and the optic disc, is very dense, it must frequently show oedema, but that remains an unexplored region clinically as well as experimentally.

\section{BIBLIOGRAPHY}

Collette, J. M., François, J., and NeEtens, A. (1955). J. Radiol. Électrol., 36, 542.

FrançoIs, J., and NeETENS, A. (1954). Brit. J. Ophthal., 38, 472.

(1956). Ibid., 40, 45.

and Collette, J. M. (1955a). Ibid., 39, 220.

(1955b). Ophthalmologica (Basel), 129, 145.

(1956a). Brit. J. Ophthal., 40, 341

(1956b). Ibid., 40, 730.

(1957). Probl. actuels Ophtal., 1, 147. 